\title{
Moving Ahead With Human-Machine Communication
}

\author{
Leopoldina Fortunati $\left.{ }^{1(}\right)$ and Autumn Edwards ${ }^{2}$ (D) \\ 1 Department of Mathematics, Computer Science and Physics, University of Udine, Udine, Italy \\ 2 School of Communication, Western Michigan University, Kalamazoo, Michigan, United States of America
}

For this volume, we selected 10 articles we found groundbreaking for their innovative contribution to the field of human-machine communication (HMC). This field becomes increasingly interdisciplinary since it attracts contributions from disciplines such as sociology and anthropology, as well as communication and media; we would like to see even more philosophy and politics. Interdisciplinarity is important to building an integrated lens through which to look at this new field and to solidifying social sciences as an attractive intellectual home for studying HMC. The range of topics addressed in these 10 articles is wide, branching in many exciting directions. However, when considered holistically as a collection, the articles in this volume deal substantially with four layers of discourse, which are relevant to moving forward the HMC project. They are as follows: (1) updates to theoretical frameworks and paradigms (MASA; Lombard \& Kun), (2) examination of ontologizing and prototyping processes (Etzrodt \& Engesser; Banks et al.), (3) a critical turn regarding gender (Liu) and ability/disability (Davis; Denhert \& Leach), and (4) exploration of HMC in organizational contexts (Gibbs et al.; Johanssen \& Wang; Piercy \& Gist-Mackey; Prahl \& Van Swol).

\section{Progressing on CASA With the MASA Paradigm and Discussing it From Another Angle}

Innovation at the theoretical level is necessary to work out a new field of research such as HMC but it is understandable that at the beginning scholars try to use the theories that they have inherited from past or contiguous fields. There are a plethora of theories available today, starting from those developed to address the field of mediated communication, passing through telephone communication (fixed and mobile) and especially through computer-mediated communication. Among these theories, we observe that the most important, theoretical development in HMC has focused on CASA (Computers as Social 
Actors), the influential paradigm proposed by Nass and colleagues in the 1990s (Nass et al., 1994; Nass et al., 1996; Nass et al., 1997). According to CASA, people treat computers in some of the ways they treat humans by mindlessly applying to them the same social rules they use in human-human interactions. In this volume of Human-Machine Communication, Lombard and Kun in their article, "Social Responses to Media Technologies in the 21st Century: The Media Are Social Actors Paradigm," revisit CASA by expanding it and launching a new paradigm: the Media Are Social Actors (MASA) paradigm. This paradigm is elaborated in a very sophisticated way by introducing the distinctions among social cues, the effects of social cues on medium-as-social-actor presence and social responses, and then by examining the role of individual differences and contextual factors. Lombard and Kun also propose consideration of mindless and mindful anthropomorphism as two complementary mechanisms for understanding MASA. Based on evolutionary psychology explanations for sociality, they offer nine formal propositions and suggestions for future research to test and apply MASA. In the previous volume of Human-Machine Communication, Gambino, Fox and Ratan (2020) first proposed an extension of CASA, arguing that humans do not necessarily implement social scripts associated with human-human interactions as predicted by CASA, but perhaps also social scripts that have been developed for interactions specific to media entities. Their extension enables us to explain previous dissonant findings and expands scholarship regarding HMC.

The problem first addressed by Reeves and Nass (1996) is the acknowledgment that the spontaneous and immediate response to media is faulty. Humans respond in social ways to mediated representations that mimic real life, but without exerting the cognitive effort to determine how to respond in the right way. There are two crucial questions that await empirical investigation. The first is: How long does this shift from perceiving media as real people, places, and things to representations of them take? The second is: What happens when people realize the true nature of the media? The problem of the delay of time in understanding the real nature of technology is an old one and is addressed both by CASA and also by the Uncanny Valley theory by Mori (1970).

It is curious that in front of all the theories elaborated to address mediated communication, the media equation and CASA framework (Nass et al., 1996; Reeves \& Nass, 1996) is identified as the one that seems to be the most suitable for helping the scholarship deal with the world of HMC. Thus, it is relevant to understand why this framework is considered so useful for this new field of studies. Gambino et al. (2020) argued that CASA is well-suited to accompany scholars in the HMC field because it is based on humans' understanding of social interaction. With the purpose of enhancing usability, they continue, designers have tried to reduce the cognitive effort it takes to use digital technologies by activating users' existing mental models. Designers and engineers create interfaces that reflect patterns of human communication and imitate offline forms of social interaction (Nass \& Brave, 2005; Shneiderman et al., 2017). In effect, CASA presents the great advantage of prefiguring the immediate, potential patterns of human attitudes and behaviors in the field of social robots and virtual assistants. We argue that, however, this will not be sufficient because the field of social robotics is not limited to designing technological artifacts equipped with some primary and secondary cues, but is complicated by the question of the anthropomorphism even at the highest degrees (see Lombard and Kun in this volume). 
Reeves and Nass (1996) have explained that people treat media as humans because their "old brains" did not evolve in a way to immediately distinguish mediated representations from their real-life counterparts. They write,

The human brain evolved in a world in which only humans exhibited rich social behaviors, and in a world in which all perceived objects were real physical objects. Anything that seemed to be a real person or place was real. During nearly all of the 200,000 years in which Homo Sapiens have existed, anything that acted socially really was a person, and anything that appeared to move toward us was in fact doing just that. Because there were absolute truths through virtually all of human evolution, the social and the physical world encouraged automatic responses that were, and still are, the present-day bases for negotiating life. . . Modern media now engage old brains. (p. 12)

They frame their argument by adding two other important elements: the first is that this incorrect perception is not only a question of the old brain but also a question of users' inattention and, second, that when users regain possession of their reasoning abilities they understand that their perceptions were wrong. In their words, "people frequently live life mindlessly and with little introspection" (p. 12) and there is "good evidence that media are real first, and false only after we think about it" (p. 13). Gambino et al. (2020) and Lombard and Kun (in this volume) have already advanced substantially the field's relationship to and application of the CASA framework. Here we would like to add new paths of discourse by arguing that, although this explanation might seem correct in evolutionary terms, it should be reframed in the light of perspectives coming from the historical, sociological, and semiotic (and hermeneutic) disciplines that we will discuss here.

From a historical point of view, we recall that in the Western world people have experienced the diffusion of automata especially during the renaissance and modernity. These automata replicated human features, as in the case of the Writer, the Musician, and the Draftsman, the three automata-androids built by Jaquet-Droz in the second half of the 18th century. The automata presented the same problem as contemporary media: they implicated a delay only after which the public could understand the truth of the technological artifact or even come to terms with the impossibility on the part of the public to understand this. In other words, the public at first glance did not understand that the automata were artifacts and this was the outcome of a deception. The Catholic Church opened a controversy on their alleged, demonic aspect, which was attributed to the magic halo that surrounded them and that derived from this delay between apparent and real/revealed nature. Through this delay, according to the Catholic Church, passed the infringement conveyed by automata as their aims were to not only surprise but also to trick the public. The related debate was connected to the old issue of "authenticity." As discussed by Baron (2013) the issue of authenticity crosses the long story of robots especially in their representation as androids or gynoids.

If we look at this problem from a sociological perspective, it turns out that humans do not always pursue authenticity and grant themselves various degrees of freedom in playing with inauthenticity. However, the foundations of any society are built upon authenticity, a basis on which humans will to some extent derogate, albeit only tactically. The implicit 
social contract, which is at the basis of the functioning of society, organizations, institutions, and sociality and which functions for mutual consent, is also based on a high degree of authenticity of the individuals and their social identities. Thus, at a certain point, one has to come back to authenticity. As Seabright et al. (2021, p. 19) argued, humans are "willing to punish those whom they believe to be cheating or unjust to others, even at a cost to themselves and even if they themselves have not been directly harmed by the cheating or unjust act" (Fehr \& Fischbacher, 2004; Fischbacher, 2001). In conclusion, our old brains already have experienced this problem of distinguishing simulation from reality, which is not a unique manifestation of contemporaneity but is much older.

Second, the development of our brains and cognitive abilities may not follow a linear growth path that facilitates more ready distinction between the seemingly real and the real. We have also to consider that newer changes to our apparatus of thought and perception could render us in some ways less rather than more skilled in dealing critically with personified objects. As Simmel argues, with modernity our old brains have weakened themselves by being increasingly exonerated to think. In his essay on "The Metropoles and the Life of Spirit" (1903/1995), he describes how in the modern world the technology embodied in objects of daily use exempts individuals from previously required gestures, skills, and efforts. While things embody an increasing number of cultural layers, people become less and less culturally equipped and capable and the dissonance that follows transforms the modalities and the very meaning of existence and experience. Let us consider, continues Simmel (p. 54), the amount of culture that has been incorporated in the last 100 years in the objects and the cultural progress of individuals in the same period of time-even only in the upper classes. From this comparison, a terrifying difference in growth emerges to the detriment of individuals and even a certain regress of their culture (in terms not of education, but sensitivity and ideality) to the extent that the individual is less and less capable of coping with the luxuriant development of objective culture. Simmel's vision has not remained alone. For example, Barthes (1957) argued that to understand society, it is necessary to focus on the myths and symbology attached to the objects of everyday life. Douglas and Isherwood (1979) pointed out that objects serve to build social alliances or alienation. For Appadurai (1986), objects have social lives, are socialized things, and have social potential. Latour (1994) stated that it is impossible to build the social only with the social, and sociologists must recognize the role of objects as mediators of social interaction. Finally, Karin Knorr Cetina (1997) observed in modern societies an "increased orientation toward objects as sources of the self, of relational intimacy, of shared subjectivity and social integration" (p. 32). In conclusion, objects, and particularly technologies, have been increasingly recognized as unintentional mediators of social relationships. These overall observations seem to be prophetic given that while we build increasingly "smart" and "intelligent" artifacts, human IQ seems to decrease in the most recent decades (Pietschnig \& Voracek, 2015). To conclude, our old brains in the last century probably have experienced a process of downsizing, which, even if recent, must be taken into account in the general framework of our reasoning.

A third and maybe most important consideration coming from semiotics is that our old brains have experienced narration (Chatman, 1980) and play since humans began to communicate through language. Oral societies communicated using forms such as narratives, myths (in particular, cosmogonies), legends, fables, and so on (Ong, 1986). When societies 
shifted from orality to literacy, the structure and mechanisms of narration were incorporated in written texts, as well. Thus, reading is a new cognitive function in evolutionary terms, because it was invented only 5,500 years ago (Dehaene, 2007; Wolf, 2007). By contrast, although it is impossible to recompose the phylogenetic history of narrative behavior and to affirm its evolutionary origin in a totally founded way, the structure and mechanisms of narration are very old and readers' brains are used to them (Cometa, 2017; Tomasello, 2005). Aristotle considered fiction a serious matter because it is capable of extending knowledge, allowing us to imagine what can happen in the future, and to be ready and open to any event (Consoli, 2011). When readers read a text, they make a pact with the authors (Sartre, 1960, p. 46), which consists of willingly suspending their disbelief in what they are told and believing in the world that is narrated to them (Eco, 2016). As readers, our brains are accustomed to cooperating in textual actualization and to considering as true the fictional notions provided by the author (Eco, 1983). Those whom authors consider as their Model Readers are, therefore, required to make this considerable "pact." Users are required to experience simulation, identification, and empathy (e.g., Rizzolati and Sinigaglia, 2006) and to share or not in what the author proposes. They have to collaborate based on their real-world competence and, when they don't, must accept what is provided by the authors. Authors not only ask readers to pretend they know things about the real world that readers don't know, but also to believe that they should pretend to know things that don't exist in the real world (Iser, 1987).

In addition to fictionality, another secret of the attraction of the narrative text is that its format has a magnitude smaller than the boundless one of the world of reality. Narrative worlds have more defined boundaries and this allows us to be more comfortable than in the real world. Although between the real and narrative worlds there is a relationship of partial identity, conceivability, and accessibility, the fictional world is more conceivable and accessible than the real world. More important is that the possible world of fiction is not an entity detached from the reality that gave it birth, but is a real part of this same reality. Eco (1985) explained clearly that possible worlds as epistemic constructs are real insofar as they are embedded, beyond syntactically, in the real world that produces them. They are not parallel; they are one inside the other and each of them participates a little in the reality of its own container. Thus, fiction requires the revision of our relationship with the real world through the ability to move in and out of the text (Montani, 2014) or to apply the two narrative faculties: decoupling and simulation (Cometa, 2017). Considering the complex relationships between fiction and reality leads us to examine play. Narration has the same function as play: Children play with dolls, kites, or wooden horses to familiarize themselves with the physical laws and with the tasks and roles that one day they will have to perform seriously. Likewise, reading stories means playing a game through which you learn to make sense of the immensity of things that happen in the real world. This is the therapeutic function of fiction and the reason why people tell stories.

The shift that people have undergone in respect to media is that they have transferred to media their experiences regarding narration and, in general, the content that media convey, and began to read the media themselves as texts (Cosenza, 2009). The relationship, the implicit contract that there is between the author and the reader, has been transferred to the relationship between the user and the medium. This displacement is a mechanism that our brains use often to approach new things. They reduce the impact of novelty by creating 
an oblique relationship with the new thing. Thus, based on what we have said so far, the motivation for why we treat media as if they were humans may be different from that proposed by Reeves and Nass (1996), because other factors-such as automata, the noticeable slowing or decline of IQ, and especially fictionality and play-intervene in the framework, and some of them are old.

The fourth consideration comes from semiotics and lies with symbols. An alternative to CASA's proposition that humans mindlessly treat computers and robots as real people because their old brains have not evolved to immediately tell the difference is that computers and robots may be interpreted as symbolic humans, understood to represent but not to be human persons. In their figural "semiotic triangle," Ogden and Richards (1923) posit that meaning is worked out in the relations between symbol (an item used to represent other things or ideas), reference (the initial thought associated with the symbol), and referent (the actual thing or object of meaning), an idea comparable to C. Peirce's earlier (1839-1914) Sign Theory (Peirce, 1998). When people respond to a virtual assistant, for example, as if it were a human, they may interpret (reference) the agent (symbol) as directly "standing for" or "standing in for" a human person (referent).

Long before computers were social actors in the research paradigmatic sense, they were human social actors in the lifeworld. As detailed by Grier in When Computers were Human (2005), in the mid-1700s, astronomers attempted to use the laws of gravity to predict the return of Halley's Comet, but the calculations proved too onerous for a single scientist. This necessitated a division of mathematical labor resulting in the creation of a new occupational role: the computer, or person whose job was to perform scientific calculations by hand. At first, computers were predominantly young men. However, by the 19th century, women, people of color, polio survivors, Jews, and others who faced grim labor prospects were hired to reduce costs. There was a concomitant association of computers with women, in specific. According to Hicks (2018), pre-electronic computation jobs were quickly feminized because they were perceived as rote and de-skilled. Ultimately, the computers' roles and functions were replicated and off-loaded to electronic machines bearing their old job titles. A similar lineage can be traced in the case of robots. As it is well known, the word "robot," derived from the Czech word for slave (robotnik), was first used in 1921 by Karl Čapek, whose play R.U.R. was about machine men that were built to work factory assembly lines and later rebelled against their human masters. Even in its earliest usage, the robot symbolized in both form and function the human being whose labor was forced and whose servitude was involuntary. Thus, human beings were the first computers and, in a symbolic sense, human beings were also the first robots.

The symbolic treatment of some people as robots continues. Several recent news stories have focused on what it means to be treated as a machine in organizational spaces. For example, Saintato (2020) writing for The Guardian suggests that people are treated like robots when corporations apply the unprecedented efficiency of the digital and data revolutions to the human workforce in terms of time management, surveillance, behavioral profiling, performance quantification, and replacement with cheaper and newer models. We contend that if one wonders whether their job is at risk of replacement by a robot, they need mainly consider the degree to which they are presently treated as a robot. This is because robotization of the human workforce tends to directly precede automation processes, as we will explain below. The idea is widespread that automation could enter factories because 
workers themselves had become the Great Industry appendages of the machines. However, at cognitive and cultural levels the notion that a person can be replaced by a robot in industry and also domestic spaces demonstrates a certain symbolic equation of the robot and human and perhaps illuminates why people sometimes treat robots like humans. This symbolic transfer is evident in our classrooms when, for instance, women express dismay at their peers' sexist abuse of female-voiced virtual assistants: "Is this how you treat (or how you wish you could treat) the women in your life?" These students express the view that such AI systems obviously are meant to represent them, to symbolize them as human women, and that disrespect of the symbol damages also the object of its reference. For them, using polite language with Alexa or Siri does not arise from the mindless application of human scripts, but from the same process that encourages careful treatment of a flag to not denigrate the nation for which it stands. More generally, this perspective can be framed in light of what Danaher (2017), in the context of sex robots, terms the "symbolicconsequences argument." Although problematic aspects of robot symbolism are perhaps removable and reformable (Danaher, 2017), symbolism itself remains endemic to social relations with robots.

Like narration and play, symbols are ancient and are constitutive of what makes humans human in the first place. From the analog virtual realities of cave paintings and human sculpture to language, to the digitally-rendered mind spaces and anthropomorphized artifacts of current technology, the ability to create and use symbols, or to overlay abstract and fictional structures onto our physical reality, is a marker of human social evolution (Danaher, 2017, p. 8; Harari, 2016). When we interpret or respond to the symbol in light of what it represents, it is not necessarily because of a naïve conflation or a mindless attribution that they are the same. Rather, it is because we are used to this surrogating process that Sneddon (2015) has articulated as taking symbols in virtue of what they represent and which governs the relational aspects of human life (Sneddon, 2015 as discussed in Danaher, 2017, pp. 7-8). Therefore, whereas CASA's "old brains engage new media" formulation leads naturally to a focus on mindless versus mindful attribution processes, these hermeneutic and semiotic interpretations of robots/media as narrative texts and symbolic humans beg scholarly attention to issues of literacy and representation, respectively.

This discourse on why people treat media as humans is only sketched and needs to be further developed and integrated. Surely, two issues need future empirical research. The first is the need to understand what happens after people have realized their mistake (i.e., that machines are not humans). A partial response might arrive from semiotics: the cooperation that is required of users needs time to unfold. The text to be read proposes itself as a becoming, dynamic process: readers actualize over time successive portions and consistent macro propositions of it (Eco, 1985). Narration requires a progressive comprehension, which is the outcome of the reader's negotiation with the text (Cecchi, 2019). In the hermeneutics of the relationship between narration and the experience of time (Ricoeur, 1985/1988), the exemplary exercise of imagination accompanies the horizon of waiting (Jauss, 1967/1969). Again, users need time to make sense of any text.

The second open issue is to understand why among the various strategies that readers generally apply to a text we have often transferred to media the naïve one. Let us outline the problem. Readers apply to texts several strategies according to their skills. There is a "naive reading" when readers identify themselves completely with the story and with the 
characters and mistake the story they are reading for true (Eco, 1983). This is obviously a "perspective error": in this case, readers do not realize that the events and characters of the narrative work have a limited existence. Then, there is an "available reading" when readers are aware of the (partially or totally) fictitious nature of a narrative text, are willing to temporarily suspend their disbelief, to accept the story as if it were true, and also the rules of the game. They identify themselves with the story, experience the emotions that the text and the author want to arouse (the ability to identify with the story of the characters is necessary to the functions of evasion and catharsis of reading, which are among the main functions sought by literature). Finally, there is a "critical reading" when readers do not foresee the identification of the reader in the story they are reading; it is a second, specialized reading which aims to criticize and interpret a text (Eco, 1983). Probably users often apply to media a naïve reading because information and communication technologies are relatively new and users have a limited repertoire, understood as the ensemble of conventions necessary to establish a situation common to the artifact and to themselves, as well as limited mental schemes and scripts. It is not surprising if the first strategy adopted by users is to apply a naïve reading and the mental schemes and scripts that users have tested in human-human communication in the real world. But after a while, as Gambino et al. (2020) argued, things change.

There is another element of the CASA theory to correct. Reeves and Nass (1996) argue that "people's responses to media are fundamentally social and natural" (p. 251). In the next section, we will see how it is more appropriate to substitute the term natural with cultural.

\section{Ontologizing and Prototyping Moves}

The second strand addressed in this volume offers two relevant articles, which advance the debate, the first on ontology and the second on prototyping. Etzrodt and Engesser, in the article "Voice-based agents as personified things: Assimilation and accommodation as equilibrium of doubt," contribute to the debate on the ontology of humans and machines (as well as animals and simple objects) by proposing a sophisticated investigation of the nature of doubt regarding voice-based agents, based on Piaget's ontological classification of object-subject and thing-person, their associated equilibration processes, and the key factors of the situation: the user and the agent. They documented that the majority of their participants classified voice-based agents into personified things, although this classification remains fragile. The notion of personified things summarizes well how the boundaries between humans and robotic technologies are becoming less clear. Much of the ontological debate on the human-machine communication field has focused so far on the increasing blurring of the boundaries between the various elements of the relation: human and machine, for example (Edwards et al., 2019; Guzman, 2020). Recently, the epistemologist Nikhil Bhattacharya, in a path-breaking seminar, argued that if we want to really progress with this question, we need to focus on the two elements of the interaction: the human and the machine (robot). In front of their blurring boundaries, there is the need to trace a dividing line that remains essential between humans and robots. Sandry (2015) articulates the value of blurred yet meaningful boundaries by drawing on N. Katherine Hayles's (2005) posthumanist argument that: 
the 'boundaries are both permeable and meaningful', such that humans can still be regarded as 'distinct from intelligent machines even while the two are becoming increasingly entwined' (2005, p. 242). She suggests that if, even as they are drawn together, a clear idea of the remaining difference between human and machine is retained, the development of 'a dynamic partnership between humans and intelligent machines' can be proposed (Hayles, 1999, p. 288). (Sandry, 2015, p. 91)

We can understand what machines are and are becoming only if we can understand who we are. Technology is a key place to study humans because humans have always lived technological lives. However, the two concepts are both elusive. So far, instead of working hard on this issue, several scholars have preferred to indulge in a kind of praise of the machines and their intelligence and smartness. We try to initiate a path that should be able to help us answer these two questions in the future, although we are afraid, much time and effort will be needed to arrive at some substantial responses.

So, what is a robot, and what are its capabilities? Merely arriving at a definition of robot is difficult (Sarrica et al., 2020). Not by chance, Nourbakhsh (2013, pp. 14-15) wrote "never ask a roboticist what a robot is. The answers change too quickly." The robot body is too multiform and too mutant to allow a univocal answer to the extent that from a semiotic perspective, they can be considered a highly variable geometrical machine (Montanari, 1999). The multiform body of robots is given by the fact that robots may assume many forms: androids and gynoids, machine-like (such as Roomba, Bimby, Turtlebot), plantoids, zoomorphic and theomorphic robots, drones, voice-based assistants, intelligent agents, computer AI programs, chatbots, ambient assistive living technologies, computational, intelligent games/storytelling devices, embodied conversational avatars, automatic health care, and educational services. The database ABOVE available in open-source format (https://www.researchgate.net/ publication/341835020_A_Comprehensive_Approach_to_Validating_the_Uncanny_Valley_ using_the_Anthropomorphic_RoBOT_ABOT_Database [accessed Nov 08 2020]) includes 251 different types of real robots even if it is far from being exhaustive. Second, changes in robots' bodies are very fast and not always intelligible, as many of these kinds of robots are still at the prototype level. The prototyping status implies that we do not know many things we should do. Bhattacharya (2020), in his seminar, raised the example of GPT-3T, a language learning program able to talk in the style and manner of a famous psychologist, to conclude that we don't really know the linguistic capabilities of machine learning, because the machine may not react the way you think. The tremendous advances that are made in this kind of computer AI programs lead them to undertake very sophisticated interpersonal conversations and give responses that you cannot anticipate. Robots have such a multiform and mutant body that it becomes difficult to talk of robots' identity as well as of robots' capabilities, in general, because there are too many differences between them.

As to the other element of communication and interaction, the human being, we pose the same questions: What is a human being? What are their capabilities regarding thinking and doing things? In what ways are these capabilities different from those of robots? Reflections about what a human being is are first of all pertinent to the philosophical field and in fact some philosophers elaborated thoughts over time, although in a non-systematic way. Bhattacharya (2020) recalls some pivotal moments and protagonists of these reflections 
and focuses on the Western Europe of the XVII century. In this century, a series of wars (like the civil war between Protestants and Catholics, the Thirty Years War, and the development of the colonization of the Americas) bloodied the world, leading philosophers to ask themselves the question of what human beings were. Thomas Hobbes tried to answer the question by embracing the old Latin phrase homo homini lupus ("man is wolf to man") and describing human society as bellum omnium contra omnes ("the war of all against all"), when the situation that characterizes the conditions of the state of nature occurs. René Descartes contributed to the reflection on the definition of what humans are by arguing that the human being, like all animals, is a machine constituted by sub-machines. Strangely enough, comments Bhattacharya (2020), "modern medicine is still based on such a hypothesis." Michel de Montaigne, living in a society experiencing colonialism, faced the problems that in America Europeans encountered very strange kinds of people (e.g., cannibals). Were they human beings or not? The answer he found to this question was that the human being is a product of the culture in which they are raised. Montaigne stated, continues Bhattacharya (2020), that if he had been raised in a cannibalistic society, he too would have been a cannibal. Human beings are raised in cultural frameworks that shape their thinking and feeling. As Tomasello (1999/2005) argued, a human nature independent from culture does not exist; human nature is culturally situated to the extent that we should talk of human natures.

Why do we have cultures? We have cultures for the same reasons for which we have societies. According to Anolli (2005), cultures are collective constructions, which give shape and substance to human existence and define a specific perspective on reality. Tomasello (1999/2005) conceptualizes culture as a process and argues that humans are the outcomes of a double evolution: biological and cultural. Evolutionary social sciences so far have reconstructed humans' evolution or by contrasting them with animals and in particular with nonhuman primates or contrasting among them key types of social organizations, such as small-scale societies and large-scale societies (Seabright et al., 2021). In the first case, the comparison has always been made with nonhuman primates, because these show a little genetic difference (which, in the case of chimpanzees, is only $1 \%$ ). What is unique to human beings, according to Tomasello (1999/2005), is a series of capabilities, which are made possible by humans' high propensity to sociability. They are the abilities to understand and interpret others as communicative and intentional agents; to build a network of bonds and motivations in the groups that are the basis of communication; to spontaneously share information and experience; to imitate the actions of others; to pursue the joint sharing of attention toward an object or event that implicates the focalization of the reciprocal psychological resources on the same object or event; to manage the dissociation between means and purposes, which, when practiced in pretend play, favors learning by simulation.

All of these capabilities are at the basis of cultural learning and lead to that symbolic condition, which for Deacon (1977) was the species-specific characteristic of humans. The great propensity for sociality that distinguishes human beings, also nourishes the processes of sociogenesis, which, according to Tomasello (1999/2005), thanks to the social cooperation of a multiplicity of individuals, are effective forms of creation and invention. These creative forms are at the base, he continues, of language and mathematics, the majority of cultural practices and artifacts, and cultural learning. All of these processes, argues 
Tomasello, have transformed some phenomena, which were typical of all the primates, such as communication, dominance, exchange, and explorative behavior, in human cultural and social institutions like language, state, money, science.

In the second case, evolutionary social scientists such as Seabright et al. (2021) looking at small-scale societies offer another series of interesting findings for our topic of interest here. They document that in this type of societies humans have an evolved cognitive specialization for reasoning about social exchange and social learning. Furthermore, in small-scale societies, continue Seabright et al. (2021), humans are used to several enjoyable activities, such as storytelling, music-making, singing and dance, sport, and communal beer-drinking. These activities, which have been handed down over time to the present day, are those we call today "forms of communication sociability" (Fortunati et al., 2013) and that play a central role in socialization, information exchange, and/or entertainment. Furthermore, in small societies, ethical behaviors are appreciated because they help the social organization. Saucier et al. (2014), for example, demonstrate that a lexical study of traits ascribable to humans in 12 isolated languages covering most habitable world regions outside of Europe show jealousy and crookedness are relatively ubiquitous human traits. Purzycki et al. (2018) similarly identified honesty and dishonesty as prominent crosscultural indicators of good and bad people, respectively. In addition to such behavioral norms, there is widespread acceptance of the idea that one should aspire to find virtuous people as social partners, and avoid anti-social individuals. Moreover, cooperation and collaboration are very much appreciated by humans in small-scale societies whereby cooperators prefer to connect to other cooperators in social networks (Smith et al., 2017; Stieglitz et al., 2017). These collaborative activities include both those that are meant to provide public goods and those that can be described as rituals, in which the activity itself represents the collective benefit being provided. Bhattacharya (2020) provides another key insight: Most of what we are is biopsychological and our selves are mostly settled on the basis of upbringing. These two elements are evolutionary products that shape our lives. Sketched above what a human is, we can initiate tracing some meaningful dividing lines between a present-day robot and human. Of course, we are not able to make a precise and exhaustive analysis and, as we noted above, both the nature of robots and concepts of humanity shift over time, but we can at least outline some elements of remaining and important distinction.

- A robot is not born from a mother and cannot experience pregnancy and giving birth.

- A robot has no infancy and is not shaped by a community of adults (experiencing primary and secondary socialization). In fact according to Gray and colleagues (2007), whereas humans are perceived to be high in agency and experience, animals like dogs are considered high in experience and low in agency, and robots are perceived to be high in agency and low in experience.

- A robot does not have consciousness of itself and its being in the world (Faggin, 2021).

- A robot does not feel emotions, amuse itself, and pretend to care.

- A robot is not a cultural subject, only a cultural object.

- A robot does not share food and drinks with humans. 
- A robot does not have an authentic comprehension of social institutions.

- A robot does not have goals or purposes, as Bhattacharya (2020) points out, "beyond carrying out a pre-assigned program."

- A robot has no conception of what humans do and why.

- A robot does not perceive the environment in sociocultural, emotional, and spiritual ways, only in a physical way.

The drawing of boundaries around and between humans and machines (i.e., ontologizing) is closely related to the process of prototyping, or determining what something exemplifies by fitting it within an overarching category. Especially when we encounter new interlocutors, relationship configurations, and interaction contexts, as is often the case in HMC, we ask ourselves, "What is it?" As the constructivist communication tradition has long stressed, prototyping is important because our answers to that question will lead us to activate certain stereotypes (what does it $d o$ ?) which will then influence perception and communication by guiding the application of mental constructs and the activation, modification, and use of interaction scripts (Edwards, 2018, p. 46; see also Edwards et al., 2019). In their article, "Forms and Frames: Mind, Morality, and Trust in Robots Across Prototypical Interactions," Banks et al. advance the knowledge on prototyping in HMC by focusing on the prototypicality of interaction, or the degree to which a human-robot interaction represents its larger interaction form. Banks et al. propose social, task, and play as three distinct higher-order interaction forms and examine via experimental methods their differential effects on how people perceive the mind, morality, and trust (worthiness) of a humanoid social robot. Although mind ascription and moral evaluations did not differ based on the interaction form, participants expressed more trust following the task interaction, a form of interaction the authors suggest may be most aligned with our common mental models regarding the nature, behavior, and skills of robots. In the end, participants' perceptions of the interactions were more influential to their trust and attitudes than were formal properties of the interaction, leading Banks et al. to conclude that "schema-aligned task interactions and perceived playfulness are gateways for building trust in robots" (p. 97). Trust remains a crucial issue in HMC. As Lutz and Tamó-Larrieux (2020) argued in Volume 1 of Human-Machine Communication ("The Robot Privacy Paradox: Understanding How Privacy Concerns Shape Intentions to Use Social Robots”) trust is a key element for developing comfort with social robots and determining their appropriate and ethical uses.

\section{Overcoming Binary Discourse: A Critical Turn in Human- Machine Communication Research}

The third major strand in this volume includes three articles that challenge dominant but unquestioned discourses of power and privilege infusing HMC. In the article "Social Robots as the Bride? Understanding the Construction of Gender in a Japanese Social Robot Product" Liu concentrates on Azuma Hikari, the beautiful anime-style girl that is produced as a hologram device by Gatebox Inc. As opposed to voice-based assistants like Siri, Alexa, and Cortana, Azuma Hikari is designed as an intimate companion, a "comforting bride" with whom to simulate marriage. Using a mixed-methods approach, Liu combines semiotic 
analysis of the official visual materials released by Gatebox Inc. with the heterogeneous engineering approach proposed by Gehl (2014) to critically consider the obscured and hidden aspects of Azuma Hikari that in daily interactions with users become salient alongside the official marketing materials. Liu's analysis reveals that Azuma Hikari leverages stereotypical representations of a Japanese "ideal bride" and reproduces through interaction an unequal gender relation where users are disciplined to play the role of "wage earner" and master-like husband. As Liu concludes, the humanization of objects is often associated with the objectification of humans. This research is a valuable contribution that encourages systematic attention to how HMC is reflective and productive of human gender relations and also models an exemplary methodological approach for doing this work.

Davis and Stanovsek, in their article "The Machine as an Extension of the Body: When Identity, Immersion, and Interactive Design Serve as Both Resource and Limitation for the Disabled," focus on the interplay between the technological affordances of a social virtual world and the people with disabilities (PWD) who interact via avatars in this online community. Arising from their ongoing, multiyear ethnographic study of embodiment among PWD in the virtual world Second Life (SL), Davis and Stanovsek address two research questions: (1) How do PWD who function as avatars report the technological affordances of virtual environments as functions of online identity in support of social or professional interaction? and (2) What elements of platform design (affordances) either support or inhibit social function among PWD in SL?

Results from thematic analysis demonstrate the important relationship between avatar choice, which may be congruent or incongruent with the user's physical self along many identity markers, and the development of identity and also the fundamental and increasing integration of technology itself with identity, ability, and access to professional and social communities. Through their analysis, Davis and Stanovsek further show that "while these affordances may allow for an expression of identity tied to ability, creativity and sociability not accessible in the physical world," they also "create new barriers to accessibility for individuals who have found freedoms in their embodied online surrogate" (p. 133).

Dehnert and Leach in their article "Becoming Human? Ableism and Control in Detroit: Become Human and the Implications for Human-Machine Communication," present a case study of the choose-your-own-adventure video game Detroit: Become Human to reveal how people may rely on ableist discourses to make sense of relationships with machines. They detail how ableist communication scripts cast machine partners as both sub- and superhuman, signifying lack and also excess in relation to the socially constructed "normal body," and how those scripts manifest in control and cyborg anxiety (i.e., "the fear that the performance and embodiment of a disabled person exposes the porous and permeable boundaries of what it means to be an able-bodied and able-minded human," p. 139). This case study serves as a demonstration and vehicle for Dehnert and Leach's broader call for critical approaches to understanding the communication scripts people use in HMC. In their words:

A critical perspective on a constructivist research paradigm in HMC attunes us to the ubiquitous yet powerful societal systems of oppression that guide communication scripts: structures such as heteronormativity and Whiteness that have been intensively theorized by critical communication scholars. (p. 138) 
Rightly, Dehnert and Leach contend that uncritical acceptance of the automatic (naïve, mindless) transfer of scripts developed in human interaction will thwart our ability to resist and rescript harmful relations, both human and human-machine.

These articles regarding gender (man and woman) and body representation (ability and disability) reveal the necessity to resume the debate that developed in the 1980s and that advocated a radical overcoming of binary thinking. In those years the feminist movement contested a knowledge resulting from an abstract form of the real, based on dialectic and structured with such characteristics to preclude women, by forbidding them access to thought and, circularly, by prohibiting thought from accessing the world of women (e.g., Bordo, 1986; Costantini et al., 1981; Harding \& Hintikka, 1983; Janssen-Jurreit, 1982; O'Brien, 1981). Negri (1981) also wrote about dialectic in recognizing the rupture of this eternal formula of Judeo-Christian thought within political discourse. But the first contestation of Western thought, the disavowal of its formulas and its categories, starting with dialectic, dualism, and beyond which everything that was there was branded with a generic label of irrational-from circumstantial knowledge to emotionality, from bodily knowledge to participatory intuition-was put in place by women. The contestation of the binary discourse was necessary for women. The feminist movement not only criticized how gender and identity had been shaped but at the same time defended all the subjects who were beyond the famous fixed tracks. Today we welcome the notion of "gender continuum," which includes third genders, agender, two-spirit, and different dimensional models of gender (Søraa, 2017), but this has been made possible by the rupture of the binary perspective.

There is the same need to overcome the binary discourse involved in the dialectic abled/disabled, which is still too often based on the stereotyped, social representation of the abled as normal and the point of reference and the disabled as abnormal and the exception (Davis, and Denhert \& Leach in this volume). This vision is not only simplistic, narrow, and stigma-generating, but it also prevents us from seeing the reality of the so-called normal, which is imbued with disability during the life cycle. When able people become elderly they face and live with many disabilities: for example, they become visuallyand hearing-impaired, they may have problems walking or have to move in a wheelchair, and so on (Cortés et al., 2003). Furthermore, chronic diseases are significant causes of disability and reduced quality of life for able people. Infancy is also a period in which children face many types of disability and need a long time to reach their muscle development and control mastery. Ability is something that children need to conquer through movement. Thus, disabled people are a very heterogeneous group and include as we mentioned above some who are "learning to be able" (children) and ex-able social groups (elderly), whereby scientific literature has increasingly begun to study them together with elderly people (e.g. Lee et al., 2021; Madhusanka \& Ramadass, 2021). The history of digital technologies has documented that the devices designed for disabled people have been a frontier of technological inclusion since they have allowed the design of better technologies for all: see the debate on universal design versus assistive technologies (Vanderheiden, 1998) and the advantages and disadvantages related to each of these approaches. 


\section{Exploration of Human-Machine Communication in Organizational Contexts}

A final group of four papers focuses on the exploration of HMC in different sectors of production. Gibbs et al., in their article "Negotiating Agency and Control: Theorizing Human-Machine Communication From a Structurational Perspective," draw on structuration theory to propose a conceptual framework to address HMC in organizational contexts. They note that in contrast with earlier organization technologies theorized primarily as tools, intelligent technologies may be considered agents with the potential to transform organizing and organizations. However, a robust understanding of the role of smart and communicative machines in organizational communication will require moving beyond individual-level analyses of agency and control. Gibbs et al. forward structuration theory (Giddens, 1984) as a means of recognizing the recursive interplay of structure and agents in which each constitutes the other; agents create structures which both enable and constrain their practices, and their practices reproduce social systems and structures. They offer a theoretical framework to explain agency in HMC as "a process involving the negotiation of control between human and machine agents" (p. 153). Through illustrative organizational examples of A/B testing, humans in the loop, and automated journalism, Gibbs et al. demonstrate the value of the dialectic of control; the "reciprocal power relationship between active agents and institutional forms of control" (p. 161) in organizational contexts which now include algorithmic as well as human and institutional forms of control. They conclude their discourse by presenting an exciting and important future research agenda for the application of the structurational framework in the HMC field.

Johanssen and Wang, in "Artificial Intuition in Tech Journalism on AI: Imagining the Human Subject," explore the field of tech journalism by presenting an interesting analysis of journalistic frames and discussing the new trend of Artificial Intuition (AI acting intuitively). Through a qualitative thematic analysis of tech journalism articles (from 20162019) that discussed Artificial Intuition as it relates to human subjectivity, Johanssen and Wang demonstrate that the narratives typically claimed intuition could make AI more efficient, autonomous, and human, and sometimes claimed that it could outperform or surpass human abilities and intuition. The rational/computation framing of tech journalism is examined in contrast to philosophical and psychoanalytic explanations of intuition, which introduce greater complexity and call for more attention to explainability, transparency, and bias in AI systems.

Piercy and Gist-Mackey in "Automation Anxieties: Perceptions About Technological Automation and the Future of Pharmacy Work" investigate workers' anxiety in respect to the diffusion of automation in the pharmacy context. Noting an increasingly technologizing work landscape, they orient their research toward the general question: "How do employees perceive the future of human-technology collaboration?" (p. 192) Specifically, they test the skills-biased technical change hypothesis (SBTC hypothesis) which predicts that low-skill work is the most likely to be transformed or replaced in automation processes by examining the mental models about automation in a sample of pharmacists and pharmacy technicians. Their results are largely supportive of the SBTC hypothesis and demonstrate the importance of examining the influence of anxieties on mental models surrounding HMC issues. 
Prahl and Van Swol in their article "Out With the Humans, in With the Machines? Investigating the Behavioral and Psychological Effects of Replacing Human Advisors With a Machine" analyze the behavioral and psychological effects of replacing humans with robots in the financial sector. The authors report the results of an experiment in which participants were tasked with making a series of financial forecasts in a low or high demonstrability situation after receiving advice from a machine advisor, a human advisor, or an advisor replaced by the other agent type (human-machine) halfway through the experiment. Human advisors were rated as broadly more favorable (expert, useful, similar), an effect magnified when the human was replaced by a machine during the experiment. Prahl and Van Swol discuss the numerous and complex factors that must be considered when effectively introducing machine advisors into organizational contexts and note that "it is not only humans who are replaced with will be unhappy; the people who work with these new machines may not be happy either" (p. 226).

All of these articles address timely and important questions related to various organizational contexts and contribute to moving the research on HMC ahead. They also indicate the need to acknowledge that the penetration of robotics, virtual assistants, intelligent agents, chatbots, and so on in the production sphere takes place along with the penetration and development of a cluster of processes or factors as indicated by Evans (2017): soft automation, digitalization, AI, big data, social media, and 3D printers. These factors interpenetrate and empower each other creating smart and networked environments both in factories and services and in the urban setting. Together, they are reshaping the industrial world in the direction of cutting production costs by increasingly reducing the use of the human labor force. However, as Horkheimer and Adorno pointed out in 1966,

what the modern-day technical civilization has of chaotic and monstrous does not derive from the very idea of a technical civilization or from some essence of technology as such. In modern society, technology has acquired by now a characteristic position and structure, whose relationship with the needs of human beings is profoundly incongruous: evil, therefore, does not derive from the rationalization of our world, but from the irrationality with which that rationalization takes place. (p. 108)

It is the perception and the experience of this irrationality that create, for example, the pharmacy workers' anxiety which Piercy and Gist-Mackey investigate or the negative emotions and mistaken behavior that decision-makers experience when a human is replaced by a machine in the financial sector, documented by Prahl and Van Swol.

Although the research on HMC in organizational contexts we publish in this volume is interesting and relevant, there is also the need for innovative research on self-driving cars. After the special issue of the International Journal of Communication (vol. 13, 2019) "Cars and Contemporary Communication: Machine, Medium, Mobility" edited by Thilo von Pape, Gerard Goggin, and Laura Forlano, it is time to advance the debate on communication between humans and this type of machine. This debate does not involve only the self-driving cars, the cars of the future, but also and especially the automation processes 
involved in the cars that we drive today and the cars that we will buy tomorrow. Important processes of robotization, as argued by Fortunati and colleagues (2019), concern current cars as well as many other machines that populate our everyday life. These processes have taken place against a backdrop in which cars have become over time a central hub of social, communication, and technology developments. Today, cars are a key place of encounter and hybridization between mobility, media use, mediated and analog communication, and activities such as driving. Furthermore, they have been transformed into a complex node of communication flows with different degrees of automation. Drivers are bombarded by flows arriving from road infrastructures such as traffic lights and road signs, from the car itself such as satnav systems and geowebs supporting driving and wayfinding, from pedestrians, as well as from car passengers. Drivers in turn have to communicate with pedestrians directly and through the car, with other cars, the road infrastructure, and the other passengers. On top of these information exchanges, Goggin (2012) argued that in-car communication also flows across multiple channels: mobile phones, internet, TV, and radio, with the consequence that drivers assume many different communicative roles: they are conversation interlocutors, users of mobile media, and audiences. It is extremely important for the HMC field and for humans that we advance the study of robotization processes in this communication context.

\section{Conclusion}

The four layers of discourse that this second volume of Human-Machine Communication contains substantially advance key debates in the field. The foundations of the major theoretical frameworks are progressing and the methodological tools are subject to ongoing innovation. Furthermore, the research methodologies used in this field are less confined to strictly quantitative and experimental ones, and increasingly integrate qualitative and mixed methods. Likewise, it is encouraging to witness critical approaches to HMC emerging alongside and also challenging the more traditional and administrative approaches to theory and practice. We still need to better understand the actual practices of use of technologies, which are at the basis of the big issues, if we want to progress substantially in this field (Suchman, 2019). However, we are aware that we face serious limitations in exploring the daily practices of use, especially of social robots, because these are still at the prototyping level and, thus, users have a very limited direct experience of them. This call for additional research on situated use practices, as well as our call for greater integration of historical, sociological, and semiotic/hermeneutic insights, for work that interrogates and challenges structures of privilege, exploitation, and oppression, and for research that extends HMC inquiry into transforming and transformative communication technologies like the automobile, is offered with excitement and appreciation for our wonderful community of researchers, theorists, and practitioners. We extend our gratitude to the brilliant, generous, and constructive scholars who comprise the editorial board and to the scientists, critics, and practitioners who submitted their excellent work. 


\section{References}

Anolli, L. (2005). Introduction. In M. Tomasello. Le origini culturali della cognizione umana (pp. 7-18). Bologna: il Mulino.

Appadurai, A. (Ed.) (1986). The social life of things: Commodities in cultural perspective. Cambridge University Press.

Baron, N. (2013). Authenticity, emotions, and ICTs. Intervalla: Platform for Intellectual Exchange, 1, 7-16.

Barthes, R. (1957). Mythologies. Éditions du Seuil.

Bhattacharya, N. (2020). “The human and the robotic: Mutual interaction," seminar held at the University of Udine the 1st December 2020.

Bordo, S. (1986). The Cartesian masculinization of thought. Signs: Journal of Women in Culture and Society, 11(3), 439-456. https://doi.org/10.1086/494250

Cecchi, D. (2019). Il lettore esemplare: Fenomenologia della lettura ed estetica dell'interazione. Rivista di estetica 71: 257-270.

Chatman, S. B. (1980). Story and discourse: Narrative structure in fiction and film. Cornell University Press.

Cometa, M. (2017). Perché le storie ci aiutano a vivere. Milano: Raffaello Cortina.

Consoli, G. (2011). L'immaginazione al lavoro. Che cosa e come conosciamo dal romanzo. [Imagination at work. What and how do we know from the novel]. ENTHYMEMA (5), 102-116. https://doi.org/10.13130/2037-2426/1756

Cortés, U., Annicchiarico, R., Vázquez-Salceda, J., Urdiales, C., Cañamero, L., López, M., Sànchez-Marrè, M., \& Caltagirone, C. (2003). Assistive technologies for the disabled and for the new generation of senior citizens: The e-Tools architecture. AI Communications, 16, 193-207.

Cosenza, G. (2009). Semiotica dei nuovi media. [Semiotics of New Media]. Enciclopedia Treccani. https://www.treccani.it/enciclopedia/semiotica-dei-nuovi-media_\%28XXISecolo\%29/

Costantini, S., Gagliasso, E., \& Tagliaferri, M. (1981). Il luogo delle ipotesi. Memoria 1: 9-27.

Danaher, J. (2017). The symbolic-consequences argument in the sex robot debate. In J. Danaher \& N. McArthur (Eds.) Robot sex: Social and ethical implications. MIT Press.

Deacon, T. W. (1977). The symbolic species. The co-evolution of language and the human brain. Norton.

Dehaene, S. (2007). Les Neurones de la lecture, Paris, Odile Jacob, trad. it. C. Sinigaglia, I neuroni della lettura, Milano, Raffaello Cortina 2009.

Douglas M., \& Isherwood B. (1979). The world of goods. Towards an anthropology of Consumption. Basic Books.

Eco, U. (1983). Lector in fabula. La cooperazione interpretativa nei testi narrativi. Bompiani.

Eco, U. (1985). Sugli specchi e altri saggi. Bompiani.

Eco, U. (2016). Sei passeggiate nei boschi narrativi. Bompiani.

Edwards, A. (2018). Animals, humans, and machines: Interactive implications of ontological classification. In A. Guzman (Ed.) Human-machine communication: Rethinking communication, technology, and ourselves (pp. 29-49). Peter Lang. 
Edwards, A., Edwards, C., Westerman, D., \& Spence, P. R. (2019). Initial expectations, interactions, and beyond with social robots. Computers in Human Behavior, 90, 308-314. https://doi.org/10.1016/j.chb.2018.08.042

Evans, S. (2017). On the efficiency of our industrial sector system as a stakeholder in our natural system. Presentation at the annual conference of the Academia Europaea "Sustainability and Resilience," Budapest, 3-5 September 2017.

Faggin, F. (2021). Silicon: From the invention of the microprocessor to the new science of consciousness [Audiobook]. Waterside Production, Inc.

Fehr, E., \& Fischbacher, U. (2004). Third party punishment and social norms. Evolution and Human Behavior, 25(2), 63-87. https://doi.org/10.1016/S1090-5138(04)00005-4

Fischbacher, U. (2001). Are people conditionally cooperative? Economics Letters, 71(3), 397404. https://doi.org/10.1016/S0165-1765(01)00394-9

Fortunati L., Lugano G., \& Manganelli A. M. (2019). European perceptions of autonomous and robotized cars. International Journal of Communication, 13(2), 2728-2747.

Fortunati, L., Taipale, S., \& De Luca, F. (2013). What did happen to body-to-body sociability? Social Science Research, 42(3), 893-905. https://doi.org/10.1016/j.ssresearch.2012.12.006

Gambino, A., Fox, J., \& Ratan, R. A. (2020). Building a stronger CASA: Extending the computers are social actors paradigm. Human-Machine Communication, 1, 71-86. https:// doi.org/10.30658/hmc.1.5

Gehl, R. (2014). Reverse engineering social media: Software, culture, and political economy in new media capitalism. Temple University Press.

Giddens, A. (1984). The constitution of society: Outline of the theory of structuration. University of California Press.

Goggin, G. (2012). Driving the Internet: Mobile internets, cars, and the social. Future Internet, 4(1), 306-321. https://doi.org/10.3390/fi4010306

Gray, H. M., Gray, K., \& Wegner, D. M. (2007). Dimensions of mind perception. Science, 315, 619. https://doi.org/10.1126/science.1134475

Grier, D. A. (2005). When computers were human. Princeton University Press.

Guzman, A. L. (2020). Ontological boundaries between humans and computers and the implications for human-machine communication. Human-Machine Communication, 1, 37-54. https://doi.org/10.30658/hmc.1.3

Harari, Y. N. (2016). Sapiens. Bazarforlag AS.

Harding, S., \& Hintikka, M. (1983). Discovering reality: Feminist perspectives on epistemology, metaphysics, methodology, and the philosophy of science. Reidel Publ.

Hayles, N. K. (1999). How we became posthuman: Virtual bodies in cybernetics. University of Chicago Press.

Hayles, N. K. (2005). My mother was a computer: Digital subjects and literary texts. University of Chicago Press.

Hicks, M. (2018). Programmed inequality: How Britain discarded women technologists and lost its edge in computing. MIT Press.

Horkheimer, M., \& Adorno, T. W. (1966). Dialettica dell'illuminismo. Einaudi, Torino 1966. [Dialectic of Enlightenment. Philosophical Fragments. Stanford University Press, 2002].

Iser, W. (1976/1987). Der Akt des Lesens. München: Fink (Trad. It. L'atto della lettura. Una teoria della risposta estetica. Bologna: il Mulino). 
Janssen-Jurreit, M. L. (1982). Sexism: The male monopoly of history and thought. Strauss \& Giroux.

Jauss, H. R. (1967/1969). Literaturgeschichte als Provokation der Literaturwissenschaft. Konstanz: Universitäts-Druckerei [Trad. It. Perché la storia della letteratura? Napoli: Guida.

Knorr Cetina, K. (1997). Sociality with objects. Social relations in postsocial knowledge societies. Theory, Culture \& Society, 14(4), 1-30. https://doi.org/10.1177/026327697014004001

Latour, B. (1994). Une sociologie sans objet? Note théorique sur l'interobjectivité, Sociologie du travail, vol. XXXIV(4), pp. 587-607 (It. Transl. Una sociologia senza oggetto? Note sull'interoggettività. In E. Landowski and G. Marrone (eds.) La società degli oggetti. Problemi di interoggetività, Roma: Meltemi. pp. 203-232).

Lee, J. M., Kim, Y. M., Rhiu, I., \& Yun, M. H. (2021). A persona-based approach for identifying accessibility issues in elderly and disabled users' interaction with home appliances. Applied Sciences, 11, 368. https://doi.org/10.3390/app11010368

Lutz, C., \& Tamò-Larrieux, A. (2020). The robot privacy paradox: Understanding how privacy concerns shape intentions to use social robots. Human-Machine Communication, 1, 87-111. https://doi.org/10.30658/hmc.1.6

Madhusanka, B. G. D. A., \& Ramadass, S. (2021). Implicit intention communication for activities of daily living of elder/disabled people to improve well-being. In G. Marques, A. K. Bhoi, V. H. C. de Albuquerque, \& K. S. Hareesha (Eds.), IoT in Healthcare and Ambient Assisted Living (pp. 325-342). Studies in Computational Intelligence 933, Springer.

Montanari, F. (1999). Dall'oggetto al fatticcio. [From the object of the story]. In G. Marrone (Ed.) C'era una volta il telefono (pp. 169-192). Roma: Meltemi.

Montani, P. (2014). Tecnologie della sensibilità. Raffaello Cortina.

Mori, M. (1970). The uncanny valley. Energy 7(49): 33-35. (K. F. MacDorman \& T. Minato, Trans.). http://www.movingimages.info/digitalmedia/wp-content/uploads/2010/06/Mor Unc.pdf

Nass, C., Fogg, B. J., \& Moon, Y. (1996). Can computers be teammates? International Journal of Human Computer Studies, 45(6), 669-678. https://doi.org/10.1006/ijhc.1996.0073

Nass, C., Moon, Y., \& Green, N. (1997). Are machines gender neutral? Gender-stereotypic responses to computers with voices. Journal of Applied Social Psychology, 27(10), 864876. https://doi.org/10.1111/j.1559-1816.1997.tb00275.x

Nass, C., Steuer, J., \& Tauber, E. R. (1994). Computers are social actors. In Proceedings of the SIGCHI Conference on Human Factors in Computing Systems (pp. 72-78). ACM. https:// doi.org/10.1145/259963.260288

Nass, C. I., \& Brave, S. (2005). Wired for speech: How voice activates and advances the human-computer relationship. MIT Press.

Negri, A. (1981). Erkenntnistheorie. Elogio dell'assenza di memoria. Metropoli 5: 50-52.

Nourbakhsh, I. R. (2013). Robot futures. Mit Press.

O'Brien, M. (1981). Feminist theory and dialectical logic. Signs: Journal of Women in Culture and Society, 7(1), 144-157.

Ogden, C. K., \& Richards, I. A. (1923). The meaning of meaning. Kegan Paul.

Ong, W. J. (2002/1986). Orality and literacy: The technologizing of the word. Routledge [Trad. It. Oralità e scrittura. Le tecnologie della parola, Bologna: Il Mulino]. 
Peirce Edition Project, \& Peirce, C. S. (1998). The Essential Peirce, Volume 2. Indiana University Press.

Pietschnig, J., \& Voracek, M. (2015). One century of global IQ gains: A formal meta-analysis of the Flynn Effect (1909-2013). Perspectives on Psychological Science, 10(3), 282-306. https://doi.org/10.1177/1745691615577701

Purzycki, B., Pisor, A., Apicella, C., Atkinson, Q., Cohen, E., Henrich, J., McElreath, R., McNamara, R., Norenzayan, A., Willard, A., \& Xygalatas, D. (2018). The cognitive and cultural foundations of moral behavior. Evolution and Human Behavior, 39, 490-501. https://doi.org/10.1016/j.evolhumbehav.2018.04.004

Reeves, B., \& Nass, C. (1996). The media equation: How people treat computers, television, and new media like real people and places. Cambridge University Press.

Ricour, P. (1983-1985/1986-1988). Temps et récit, 3 voll. Paris: Gallimard. [Trad.It. Tempo e racconto, 3 voll. Milano: Jaca Book].

Rizzolatti, G., \& Sinigaglia, C. (2006). So quel che fai. Milano: Raffaello Cortina.

Saintato, M. (2020, Feb 5). 'I am not a robot': Amazon workers condemn unsafe, grueling conditions at warehouse. The Guardian. Retrieved March 15, 2021, from https://bit. ly/300d8ye

Sandry, E. (2015). Robots and communication. Palgrave.

Sarrica, M., Brondi, S., \& Fortunati, L. (2020). How many facets does a "social robot" have? A review of scientific and popular definitions online. Information Technology \& People, 33(1), 1-21. https://doi.org/10.1108/ITP-04-2018-0203

Sartre, J.-P. (1948/1960). Qu'est-ce que la littérature? Paris: Gallimard [trad. it. Che cosè la letteratura? Milano: Il Saggiatore].

Saucier, G., Thalmayer, A. G., \& Bel-Bahar, T. S. (2014). Human attribute concepts: Relative ubiquity across twelve mutually isolated languages. Journal of Personality and Social Psychology, 107(1), 199-216.

Seabright, P., Stieglitz, J., \& Van der Straeten, K. (2021). Evaluating social contract theory in the light of evolutionary social science. Evolutionary Social Sciences, online first, pp. 1-45. https://doi.org/10.1017/ehs.2021.4

Shneiderman, B., Plaisant, C., Cohen, M. S., Jacobs, S. A., \& Elmqvist, N. (2017). Designing the user interface: Strategies for effective human-computer interaction (6th ed.). Pearson

Simmel, G. (1903/1995). Die Großstädte und das Geistesleben [trad.ingl. The Metropoles and the Life of Spirit; trad.it. La metropoli e la vita dello spirito, edited by P. Jedlowski: Roma, Armando Editore, 1995].

Smith, D., Schlaepfer, P., Major, K., Dyble, M., Page, A., Thompson, J., Chaudhary, N., Salali, G., Mace, R., Astete, L., Ngales, M., Vinicius, L., \& Migliano, A. (2017). Cooperation and the evolution of hunter-gatherer storytelling. Nature Communications, 8, 1853.

Sneddon, A. (2015). Symbolic value. Journal of Value Inquiry, 50(2), 395-413. https://doi. org/10.1007/S10790-015-9519-4

Søraa, R. A. (2017). Mechanical genders: How do humans gender robots? Gender, Technology and Development, 21(1-2), 99-115. https://doi.org/10.1080/09718524.2017.1385320

Stieglitz, J., Gurven, M., Kaplan, H., \& Hopfensitz, A. (2017). Why household inefficiency? An experimental approach to assess spousal resource distribution preferences in a subsistence population undergoing socioeconomic change. Evolution and Human Behavior, 38, 71-81. https://doi.org/10.1016/j.evolhumbehav.2016.07.002 
Suchman, L. (2019). If you want to understand the big issues, you need to understand the everyday practices that constitute them: Lucy Suchman in Conversation With Dominik Gerst \& Hannes Krämer. Forum: Qualitative Social Research, 20(1). https://doi.org/ $10.17169 /$ fqs-20.2.3252

Tomasello, M. (1999/2005) The cultural origins of human cognition. Harvard University Press [Trad. it. Le origini culturali della cognizione umana. Bologna: il Mulino].

Vanderheiden, G. (1998). Universal design and assistive technology in communication and information technologies: Alternatives or complements? Assistive Technology: The Official Journal of RESNA, 10(1), 29-36. https://doi.org/10.1080/10400435.1998.10131958

von Pape, T., Goggin, G., \& Forlano, L. (Eds.) (2019). Cars and contemporary communication: Machine, medium, mobility. International Journal of Communication, 13, 26762683.

Wolf, M. (2008/2009). Proust and the squid. Harper Perennial [Trad. It. Proust e il calamaro. Milano: V\&P]. 